DOI 10.37882/2500-3682.2020.11.20

\title{
НАУЧНО-ТЕОРЕТИЧЕСКОЕ ОСМЫСЛЕНИЕ МЕТОДА НАРРАТИВНОГО АНАЛИЗА И ЕГО РОЛИ В ПСИХОЛОГИИ ЛИЧНОСТИ
}

\section{SCIENTIFIC-THEORETICAL CONCEPTUALIZATION OF THE NARRATIVE ANALYSIS METHOD AND ITS ROLE IN PSYCHOLOGY OF PERSONALITY}

\section{Z. Myasnikova}

Summary: The method of narrative analysis as an interdisciplinary area is discussed in the article. The approaches of various researchers to theoretical and practical aspects of narrative analysis were studied by the author of the article.

The aim of the article lies in learning of narrative analysis method, defining its important role in psychologist's advisory practice.

The functions of narrative analysis were defined there by the method of system analysis of scientific sources/

Work practice with narrative data was analyzed there. It helped to reveal methodological difficulties in the process of interpretation of analysis results.

The kinds of narrative analysis were considered. Among them there are biographical narrative interview, structured interview and others. In the conclusion the author defined narrative analysis as a deep, creative process, which requires a researcher to be highly competent specialist.

Keywords: narrative, narrative analysis, method, experience, life way, interview, psychology of personality, narration, processing of results, interpretation.
Мясникова Зоя Вячеславовна
myasnikovazoya@yandex.ru

Аннотация: В статье рассматривается метод нарративного анализа как междисциплинарная научная область. Автором были изучены подходы различных исследователей к теории и практике нарративного анализа.

Цель статьи заключается в исследовании метода нарративного анализа, определении его важной роли в консультативной практике психолога.

Методом системного анализа научных источников были обозначены функции нарративного анализа.

Была проанализирована практика работы с нарративными данными и выявлено наличие методологических сложностей при интерпретировании результатов анализа.

Были рассмотрены виды нарративного анализа, в числе которых - биографическое нарративое интервью, структрированное интервью.

В качестве выводов автор определил нарративный анализ как глубинный, творческий процесс, требующий от исследователя высокого уровня компетенции и времени.

Ключевые слова: нарратив, нарративный анализ, метод, опыт, жизненный путь, интервью, психология личности, повествование, обработка результатов, интерпретирование.
$\mathrm{H}$ арративный анализ (от англ. narrative - описательный, повествовательный) как инструмент для определения идентичности личности уже давно привлекает внимание исследователей гуманитарного поля. Нарративный подход представляет собой междисциплинарную научную область, которая начала свое развитие в рамках литературоведения, философии, социологии, истории, и выполняет преимущественно описательную функцию. Иными словами, автор через текст доносит до читателя идею своего произведения, а читатель интерпретирует ее через свое восприятие. Впоследствии нарратив стал широко использоваться для осмысления нехудожественных текстов, в которых в центре проблемы - личность и ее идентичность.

Следует подчеркнуть, что нарратив чаще используется в психологических исследованиях, в связи с чем важно осмысление потенциала данного понятия для психологии. Это требует глубинной проработки имеющегося научно-практического материала. Если рассматривать нарративную психологию в качестве отдельной области психологии, то невозможно не признать, что это современная, активно развивающаяся научно-исследовательская сфера.

Разные ученые, занимающиеся исследованиями в данной сфере, по-своему трактуют нарратив. Одни в своих работах пишут о нарративном методе, другие - о нарративной парадигме, нарративном подходе, нарративном анализе, нарративном интервью и нарративном принципе. Такое многообразие смыслов, вкладываемых в данную научную категорию, свидетельствует об отсутствии единого понимания ее теоретической составляющей и сложностях, которые возникают с применением нарратива на практике. Интерес, который ученые проявляют к категории нарратива, заключается в смысловом содержании жизненного опыта личности и способах его конструирования. 
Научные труды У. Джеймса, Т. Сарбина, Дж. Шоттера, Р. Харре, Дж. Бруннера, К. Мюррея выступают в качестве ключевых источников нарративного подхода в психологии. В понимании исследователей нарратив позиционируется как культурно-востребованная форма переживания времени, структурирования и упорядочивания личностного опыта, через который становится очевидна реальность жизненных событий.

Так, Р. Харре называет нарратив важным конструктом, который позволяет личности структурировать понимание себя и своего жизненного пути [5]. Дж. Бруннер придерживается исследовательской позиции, согласно которой нарратив передает понимание того, как субъекты взаимодействия выстраивают коммуникацию [1]. Т. Сарбин определяет нарратив как рассказ о природе человеческого поведения, когда люди в процессе анализа собственного опыта упорядочивают его, опираясь на свои жизненные истории и истории других людей [5]. К. Мюррей воспринимает нарратив как повествование истории и, в частности, истории своей жизни, где отражаются изменения качества опыта (детство, юность, зрелость) и связанные с этим переживания времени, памяти $[2]$.

Есть среди исследователей нарративного подхода и те, которые считают неправильным выделять нарративную психологию в качестве отдельного научного раздела как социальную, возрастную, общую психологию. Так, по мнению Эллиот Мишлер, следует избегать осмысления нарративного подхода изолированно по дисциплинарным категориям [3]. На наш взгляд, такая позиция справедлива по отношению к нарративу, который по определению является междисциплинарной областью.

Традиционно сторонники нарративного подхода разделяют его на два теоретических направления. Согласно первому направлению, личность понимается как текст, а понимание личностью себя самой тождественно пониманию текста. Второе направление определяет нарратив как самоопределение личности, при котором понимание личностью себя приравнивается к осознанию своей социальной принадлежности. Оба направления поддерживают идею о том, что построение реалистичной картины осуществляется посредством языка, как в письменной, так и в устной формах.

Таким образом, нарратив представляет собой форму переживания времени, структурирования и упорядочивания личностного опыта, инструментарий для понимания и распознавания открывшейся реальности. Нарративный метод позволяет личности погрузиться в проработку памяти, в процессе чего описанные жизненные события пополняются деталями и наделяются смыслом, вследствие чего наблюдается глубокий терапевтический эффект.
Анализ научных источников по теории нарратива, в которых определяется понятие нарративного метода и подходы исследователей к его осмыслению, позволяет нам выявить и обозначить основные функции нарратива:

1. Форма понимания. Подразумевает возможность распознать реальность, которая открылась в процессе нарративного анализа.

2. Форма социального взаимодействия. Позволяет выявить социальное окружение, каким образом личность взаимодействует с другими людьми.

3. Способ переживания времени. Дает возможность рассказчику (нарратору) погрузиться во временные отрезки своего жизненного пути (детский возраст, юность, зрелость).

4. Форма организации и переживания событий. Позволяет структурировать наиболее важные жизненные события и пережить их снова.

5. Инструмент упорядочивания опыта. Дает возможность поэтапного выстраивания опыта в соответствии с временными отрезками жизненного пути.

6. Инструмент структурирования памяти и еe регулярной реконструкции. Позволяет совершить возврат к событиям прошлого, погружаясь в детали.

7. Инструмент конструирования идентичности. Делает возможным распознавание личности, определение ее предназначения, «Я-конструкта».

8. Форма самопрезентации. Позволяет через «рассказ о себе» построить представление о личности, ее опыте, жизненной истории.

И если с теоретической составляющей нарратива все понятно, по-настоящему сложной и требующей осмысления выступает практика работы с персональными данным - сбор и обработка аналитических данных. Методологические затруднения вызваны рядом спорных вопросов, например, какими критериями и параметрами следует руководствоваться психологу при формулировании выводов и решений после применения метода нарративного анализа.

Основным методом нарративного исследования выступает анализ историй, где ключевыми эмпирическими объектами представлены структурированные и неструктурированные рассказы: истории о себе (self narrative) и истории жизни (life narrative) [5]. Указанные типы повествования выполняют, на наш взгляд, более мощную психологическую нагрузку в структурировании опыта и построении идентичности личности, поскольку позиция исследователя в них тождественна позиции рассказчика (нарратора).

В качестве материалов для нарративного анализа могут быть использованы различные текстовые источники, устные и письменные. К ним относятся личные до- 
кументы (автобиографии, письма, дневники, материалы личных страниц в социальных сетях, электронные дневники), тексты, которые написаны по просьбе исследователя, занимающегося нарративным анализом, а также материалы интервью [6]. Выступая в качестве метода, наиболее адекватного требованиям и специфике методологического поля нарративного анализа, интервью традиционно стало популярным и активно используемым среди исследователей нарратива.

Примечательно и очень ценно и то, что интервью представляет собой не только инструмент для эмпирического сбора данных, но и сферу для формулирования новых гипотез, которые возникают в процессе исследования, что, в свою очередь, является основным отличием данного качественного подхода от любого количественного.

Одним из видов интервью выступает нарративное биографическое интервью. На наш взгляд, данный метод обладает высокой степенью эмоциональной вовлеченности всех участников коммуникативного процесса. Согласно авторской позиции Е. Мещеркиной, «стимулирование респондентов на рассказы о своем жизненном опыте и предоставление им свободы при выборе сюжетов и тем для повествования» определено ключевой задачей нарративного биографического интервью [7].

По мнению исследователей теоретического и практического полей данного метода, спонтанное изложение историй собственной жизни вызывает определенные сложности у респондентов. Дж. Брунер в своей статье писал, что большая часть опрашиваемых не смогла в течение сорока минут изложить историю своей жизни [5]. Отечественные исследователи Е. Мещеркина и В. Семенова также подчеркнули сложность рассказывания личных историй жизни в искусственно созданных ситуациях на протяжении длительного времени. Авторы обосновывают свою позицию, указывая на недостаточно развитую рефлексию относительно собственного опыта.

Кроме того, исследователи обращают внимание еще на одну сложность интервью: готовность либо неготовность респондента рассказывать о собственном опыте, когда интервью делится на рассказываемый и нерассказываемый опыт. К нерассказываемому опыту следует относить личную, интимную и даже в некоторой степени опасную для респондента информацию, поскольку она включается в повествование с большими ограничениями. Также из повествования исключаются те фрагменты опыта, которые были травматичны для рассказчика. Подобная информация становится недоступной для исследователя, закрывает некоторые важные стороны его опыта и требует повышенного внимания к деталям.

Наиболее совершенным и удобным для эмпириче- ского анализа выступает, по нашему мнению, структурированное нарративное интервью, разработанное и апробированное американским нарративным психологом Дэном МакАдамсом. Согласно авторской методике, структурированное нарративное интервью представляет собой форму беседы (письменной или устной), где порядок расположения вопросов, блоков и модулей установлен исследователем предварительно. Данный метод нарративного анализа продуктивен еще и потому, что учтена логика повествования, согласно которой вопросы поддерживают интригу истории жизни, опыта личности.

Размышляя о структуре нарратива, традиционно он помещен в такую систему: равновесие - нарушение равновесия - восстановление равновесия. В связи с этим Дэн МакАдамс намеренно предлагает начинать выборку жизненных историй и ситуаций с тех эпизодов, где отмечаются какие-либо отклонения от нормы.

По мнению исследователей нарративного психологического поля (Дж. Брунер, Дэн МакАдамс), очень важным является формулирование специальной инициативной формулы, которая бы побуждала нарратора к рассказыванию. Это своего рода обращение к человеку, который будет принимать участие в эксперименте, исключающее директивность и авторитарность. Формула должна быть понятной слушателю и располагать его к раскрытию. Если нарративный анализ предполагается в устной форме, очень важно, чтобы за инициирующей формулой следовал рассказ, не прерываемый исследователем-практиком. Это, на наш взгляд, позволит нарратору самому определять порядок и ход повествования. Техника активного слушания также способствует лучшему раскрытию рассказчика.

В некоторых интервью МакАдамс предложил идею о предоставлении рассказчику позиции теоретического аналитика собственной истории жизни и опыта. Для этого рассказчику требовалось давать оценку событиям собственной жизни, анализировать их и разъяснять. По теории МакАдамса, это группа вопросов, задаваемых применительно к истории жизни с использованием образцов, эталонов, базовых сюжетов [5]. Данная группа вопросов, на наш взгляд, имеет видимый терапевтический эффект, поскольку способствует повышению критичности и рефлексии прошлого опыта, а также усиливает активность и самостоятельность личности при формулировании определений относительно формата собственной истории жизни и предшествующего опыта.

В процессе научно-теоретического осмысления метода нарративного анализа следует упомянуть еще об одной его очень важной и методологически сложной фазе - обработка и интерпретация материала, полученного в ходе исследования. Именно эта фаза анализа 
вызывает наибольшие сложности, поскольку у исследователей нет единых правил и алгоритмов, позволяющих последовательно и логично перейти от фазы сбора эмпирического материала к фазе его обработки и анализа. В каждом отдельном нарративе от психолога требуется разработка уникальной схемы его исследования, создание базы для интерпретации, которая бы учитывала особенности именно этого конкретного нарративного материала.

Так, по мнению Джонатана Поттера, английского дискурсивного психолога, ключевыми качествами исследователя в нарративном методе определена «аналитическая ментальность, туманное и волшебное свойство» [8]. Данное качество предполагает способность исследователя создавать из неосвоенного эмпирического материала освоенный, из неструктурированного - структурированный, из неупорядоченного, неорганизованного - упорядоченный. Возникает логичный вопрос, который серьезно обсуждается в сфере качественных методов исследования: возможно ли обучиться такому качеству? Нам близка позиция И. Штейнберга, известного отечественного специалиста в этой области, который убежден, что качеству «аналитической ментальности» обучиться вполне реально, однако не в рамках аудиторных занятий, а в реальной ситуации исследования [7].
Научно-теоретическое осмысление метода нарративного анализа позволило нам определить нарратив в качестве формы создания жизненной истории (life making). Иными словами, посредством нарратива происходит структурированный сбор фактов человеческого существования в логично выстроенной последовательности. Нарратив подобен интриге, когда события повествования превращаются в элементы целостной истории жизни (завязка - кульминация - развязка).

Нарратив также позволяет рассказчику (нарратору) находить и выражать смыслы в повествовании. Значение нарратива постоянно претерпевает развитие, и в настоящее время это не только способ извлечения фундаментальных эмпирических данных, но и позиционирование исследователя в роли рассказчика (нарратора).

Безусловно, научно-исследовательское поле нарративного анализа в сфере психологии и психотерапии не может быть исследовано в качестве константной категории, поскольку постоянно претерпевает изменения и введение новых возможностей применительно к сбору данных и к их интерпретации. Нарративный анализ, с нашей точки зрения, это глубинный, творческий процесс, предполагающий большие затраты временных и энергетических ресурсов исследователя и требующий высокого уровня его компетенции.

\section{ЛИТЕРАТУРА}

1. Кадырова Р.Г. Теория нарратива и нарративный анализ в психологии / Р. Г. Кадырова // Вектор науки ТГУ. - Баку, 2012. - № 2 (9). - с. 126-128.

2. Кроссли М. Нарративная психология. Самость, психологическая травма и конструирование смыслов / М. Кроссли. - М.: ДМК- Пресс, 2013. - 284 с.

3. Кутковая Е.С. Нарратив в исследовании идентичности / Е. С. Кутковая // Национальный психологический журнал. - 2014. - № 4 (16). - c. $23-33$.

4. Нуркова В.В. Рассказывать о себе, рассказывать себя, рассказывать собой: автобиографический нарратив с позиций культурно-деятельностного подхода / В.В. Нуркова // Развитие личности. - 2010. - № 1. - с. 74-92.

5. Орлова Г.А. Методическое пособие к спецкурсу «Нарративные методы анализа в психологии личности» / Г.А. Орлова. - Ростов-на-Дону, 2007. - 40 с.

6. Сапогова Е.Е. Возможности анализа автобиографических нарративов в обучении психологическому консультированию / Е.Е. Сапогова // Профессиональное становление специалиста: Сб. науч. трудов. - Ростов-на-Дону, 2006. - с. 124-142.

7. Терехова Т.А., Малахаева С.К. Нарративный анализ как понимающий метод [Электронный ресурс] / Т.А. Терехова, С.К. Малахаева // Гуманитарный вектор. Серия: Педагогика, психология. - 2015. - № 1 (41). - Режим доступа: https://cyberleninka.ru/article/n/narrativnyy-analiz-kak-ponimayuschiy-metod

8. Турушева Ю.Б. Нарративный подход к проблеме развития смысловых образований / Юлия Борисовна Турушева: дис. .... канд. псих. наук. - Москва, 2017. -170 c. 